\title{
Modelling of motor vehicle operation for the evaluation of pollutant emission and fuel consumption
}

A novel approach to modelling of motor vehicle operation by employing special test cycles threated as realizations of the stochastic process of vehicle velocity is presented. The families of test cycles were designed to simulate driving conditions in street congestion, urban, extra-urban, and high-speed traffic. The data necessary for the development of test cycles was obtained in the empirical investigations conducted in real road traffic. The recorded velocity time-histories were analysed in the time, frequency, and process value domains. Fragments of the velocity vs. time curves, representative for the considered driving conditions, were selected to design test cycles. The statistical examination of those test cycles demonstrated that individual process realizations are similar to each other and to all the process realizations recorded during the empirical tests.

Key words: vehicle driving test cycles, pollutant emission, fuel consumption

\section{Introduction}

To acquire knowledge of the operational properties of automotive engines, in particular their economic performance in terms of fuel consumption and their ecological characteristics related to pollutant emission, vehicle driving test cycles are designed for the simulation of actual vehicle drive conditions. This stems from the fact that for similar characteristics of the power transmission systems in motor vehicles designed for comparable applications (e.g. motor cars), the process that determines the state of operation of an internal combustion (IC) engine during vehicle drive is the vehicle velocity, while the engine operation state is the main factor the operational properties of IC engines depend upon. The IC engine operation state is characterized by the quantities that define the intensity of engine operation, the measure of which is the effective power, and by the thermal state of the engine. The thermal state of an IC engine is defined by the set of temperatures of engine parts and operating fluids (engine oil and coolant, in most cases). The intensity of engine operation is described by the rotational speed of the engine crankshaft and a quantity characterizing the engine load, predominantly torque or mean effective pressure [7].

The earliest vehicle driving test cycles were developed for the purposes of pollutant emission and fuel consumption evaluation within type-approval testing of motor cars and light trucks (delivery vehicles). It was natural then that the vehicle driving test cycles used in the procedures of type approval of motor cars, light trucks, motorcycles, and mopeds have become standards, chiefly in the EU, USA, and Japan [13]. However, there was a need to acquire knowledge of the properties of vehicles operated in conditions other than those adopted in the type-approval procedures. Therefore, vehicle driving test cycles were developed at many research centers to simulate vehicle drives in various traffic conditions, ranging from street congestions to motorway traffic.

For the purposes of determining pollutant emission characteristics in the INFRAS AG software [17], numerous test cycles were prepared, applicable to motor cars, light trucks, motorcycles, and mopeds, as well as to motor trucks and buses [6]. Works on the tests for the simulation of various conditions of vehicle drive were also carried out in connection with the works on the inventory of pollutant emission within the CORINAIR (Core Inventory of Air Emissions) program [14]. Within the implementation of the European Artemis program, a system of Common Artemis Driving Cycles has been prepared, which consists of test cycles that simulate motor car drives in various traffic conditions [1, 3]. Another example of the vehicle driving test cycles is the system of test cycles developed at a French institute INRETS (Institut National de Recherche sur les Transports et leur Sécurité, i.e. National Institute of Transport and Safety) [23].

Many attempts were also made to undertake research works on the conditions of motor vehicle drive. The problem of modelling the motor vehicle drive in street congestions has been considered in publications by Bando et al. [2], Barth, Scora, and Younglove [4], Treiber, Hennecke, and Helbing [29]. In publications by Gong et al. [15], Souffran, Miègeville, and Guérin [27] the use of Markov chains for modelling the motor vehicle drive has been presented. In the works described by Lyons et al. [20], Schwarz [26], Tong, Hung, and Cheung [28] characteristics of pollutant emission from IC engines in static states were used for the simulation of pollutant emission in the conditions of vehicle drive on fast traffic roads. Studies by Jacobs [16], Lee and Filipi [18], Lin and Niemeier [19], Miller [22] have been devoted to the methods of modelling motor vehicle drive with the use of the theory of stochastic processes.

A definite majority of the vehicle driving test cycles having been developed are causal (deterministic) time histories of vehicle velocity (i.e. when applied as a test input, they determine the quantities measured as the test output). Publication by Barlow et al. [3] contains a set of most of the cycles having been published, including a summary of their zero-dimensional characteristics (such as test time, distance travelled, average velocity, standard deviation of the velocity, etc.) that make it possible to make comparisons between the properties of individual test cycles. 
The aim of this paper is to present an authorial concept of motor vehicle driving test cycles treated as a set of realizations of the stochastic process of vehicle velocity. Such an approach enables not only the investigation of motor vehicle properties in conditions simulating its operation in real road traffic but also the evaluation of the uncertainty of measurements carried out in random vehicle operation conditions [9]. The paper makes a substantial extension of the paper by Chłopek et al. [10] and widens the scope of the analysis, creating a more detailed picture of modelling of motor vehicle operation for the evaluation of pollutant emission and fuel consumption.

\section{Design of driving test cycles}

Several different methods can be adopted to design driving test cycles. They can be assigned into three general groups:

- methods based on the assumption of a predefined time history of the relative vehicle velocity, which refers to the maximum velocity;

- methods based on the principle of faithful time-domain simulation of the time history of the vehicle velocity;

- other methods, based on the analysis of the velocity process characteristics in other domains, such as time, frequency, or process values.

The criterion for assessing the adequacy of the driving cycles is the similarity between zero-dimensional characteristics of the velocity processes in the driving cycles and during actual vehicle operation $[1,7,23]$. Those characteristics may be determined in the domains of: time, independent variable of the integral transformation of a time history of the vehicle velocity (usually frequency), or process values [7]. The most commonly used zero-dimensional characteristics in the time domain are the following $[5,7$, 24]: average value, root-mean-square (RMS) value, variance, standard deviation, median, extreme values, proportions (distribution) of values in specific intervals. In the frequency domain, the amplitude and phase characteristics are predominantly determined. Their values for specific frequencies of their averaged values for specific frequency intervals are taken as representative point characteristics [7]. In the domain of process values, the most important characteristic is the probability density function and its zero-dimensional characteristics. The latter include: average value, most probable value, variance, or parameters of the standard probability density functions that approximate the probability function under analysis, in accordance with the criterion adopted [7].

The design of the test cycles in accordance with the principle of faithful time-domain simulation of the time history of the vehicle velocity can be performed in two ways. The first is the selection of fragments of the velocity vs. time curves that are representative for the velocity process under analysis. The other is the synthesis of selected fragments, considered representative for the velocity process under analysis.

The method of designing vehicle driving test cycles by assuming a predefined time history of the relative vehicle velocity referred to the maximum vehicle velocity has been employed in the preparation of numerous test cycles. The examples are the European type-approval test NEDC (New European Driving Cycle), consisting of the UDC (Urban
Driving Cycle) and EUDC (Extra Urban Driving Cycle), or the Japanese type-approval test Japan 10-15 Mode [13].

Many of the tests designed in accordance with the principle of faithful time-domain simulation of the time history of the vehicle velocity were built by synthesizing selected fragments of such a time history that are considered representative for the velocity process under analysis. Examples of the test cycles of this kind are those developed in the USA for the testing of both motor vehicles (such as FTP75 , i.e. Federal Test Procedure) and IC engines (such as HDDTC, i.e. Heavy Duty Diesel Transient Cycle) [13]. Similarly, motor vehicle test procedures have been developed in order to determine pollutant emission and fuel consumption characteristics, utilized then for the preparation of a database for the INFRAS AG software [17]. The methods of building such tests have been presented in publication of BUWAL and INFRAS [6]. To select the fragments that would be representative for the vehicle velocity process under analysis from the recorded velocity vs. time curves, the method of cluster analysis was used [30]. As the criteria for comparisons, more than ten zero-dimensional characteristics of the velocity process were adopted, including the average velocity value and the average value of the product of absolute values of vehicle velocity and acceleration. Then, the selected fragments, found to be representative for the vehicle velocity process under analysis, were used to compile vehicle driving test cycles, which would be consistent with the vehicle velocity processes under consideration in accordance with the comparison criteria adopted, with the use of the Monte Carlo method [8, 21]. Thus, vehicle driving test cycles were set up, which represented motor vehicle drives in various traffic conditions, including street congestions and motorway traffic, as well as the traffic in streets with specific vehicle traffic intensities, with or without traffic lights.

A novel approach to modelling of motor vehicle operation by employing special test cycles threated as realizations of the stochastic process of vehicle velocity was developed at Automotive Industry Institute (PIMOT). Families of vehicle driving test cycles have been prepared within research project [10], to simulate the conditions of motor car drives in street congestion, urban, extra-urban, and high-speed (motorway and expressway) traffic.

\section{Materials and methods}

The data necessary for the preparation of the vehicle driving test cycles was obtained in empirical investigation conducted in real road traffic with the use of Honda Civic passenger car (Fig. 1). It was manufactured in 2000 and provided with a four-cylinder in-line spark-ignition engine of $1400 \mathrm{~cm}^{3}$ capacity, meeting the requirements of the Euro 3 exhaust emission standard.

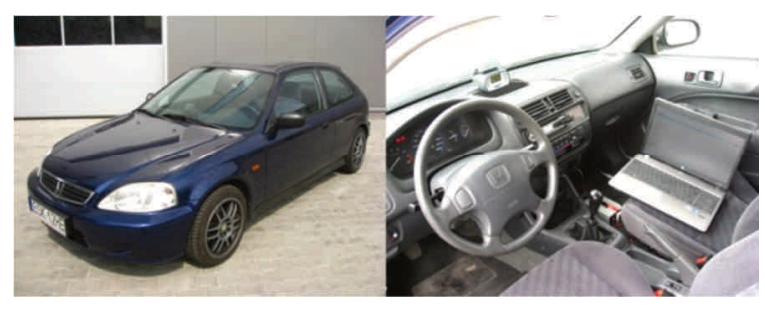

Fig. 1. Vehicle used in the empirical investigation 
The empirical investigation included real-time measurements and recording of vehicle velocity, engine speed, engine steering, and vehicle location, with $10 \mathrm{~Hz}$ sampling frequency. The signals were recorded from On-Board Diagnostics system (OBD II) of the car, using OBD II reader Automex AMX530, and by GPS positioning device Racelogic Performance Box. For further processing of the signals obtained, the Golay-Savitzky smoothing filter [25] was adopted, with approximation to a polynomial of degree 2 for nine measuring points.

The vehicle operation was modelled to represent four categories of driving conditions:

- urban traffic congestions (denoted as CT),

- urban traffic (without congestions) (denoted as UT),

- extra-urban traffic (denoted as RT),

- high-speed (motorway and expressway) traffic (denoted as HT).

Vehicle velocity samples collected in empirical investigation were divided into those four categories, giving sets of the following cardinality: 19, 34, 16, and 8, respectively.

For each category of vehicle operation four driving test cycles were designed, in accordance with the criterion of faithful time-domain simulation. With this objective in view, the fragments of the velocity vs. time curves recorded during vehicle drives in real road traffic were chosen for which the values of the selected characteristics were close to the values of the characteristics corresponding to all the sets. As the top priority criterion, the average value was taken. The next criterion in was the standard deviation.

The designed driving test cycles were further analyzed in the time domain, frequency domain, and process value domain, with determining, inter alia, extreme values, average value, variance, median, and quartile deviation [5, 24]. The power spectral density of vehicle velocity vs. frequency curve was also plotted.

\section{Driving test cycles designed at Automotive Industry Institute}

The time histories of the vehicle velocity for individual vehicle operation models (CT, UT, RT, and HT) is presented in Figure 2. They are treated as realizations of stochastic processes of velocity for the said models.

The properties of the designed driving test cycles, representing vehicle operation models, are summarized in Table 1 , showing selected zero-dimensional characteristics of the vehicle velocity process, i.e. average value and extreme values of the vehicle velocity.

The driving cycles for each vehicle operation model have close values of the considered zero-dimensional characteristics (Ch): maximum value (MAX), average value $(\mathrm{AV})$, median (M), standard deviation (D), and quartile deviation (DQ). Figure 3 shows a comparison of those characteristics for individual driving test cycles (CT1-4, UT1-4, RT1-4, and HT1-4), for four test cycles of the same category $\left(\mathrm{CT}_{\mathrm{AV}}, \mathrm{UT}_{\mathrm{AV}}, \mathrm{RT}_{\mathrm{AV}}\right.$, and $\left.\mathrm{HT}_{\mathrm{AV}}\right)$, and for all velocity samples collected in empirical investigation in real road traffic of the same category $\left(\mathrm{AS}_{\mathrm{AV}}\right)$.

It can be clearly seen that the characteristics under assessment are similar to each other. With respect to the assessment criteria adopted, a significant similarity exists between the average values as well as the standard devia- tion values. The median and quartile deviation values are also close in individual tests, which is of considerable importance because the distributions of the processes under investigation are markedly asymmetric. Minor differences occur only in the case of the maximum value of the velocity. However, taking into account the randomness of the velocity processes, the maximum value for the whole set may be randomly high.
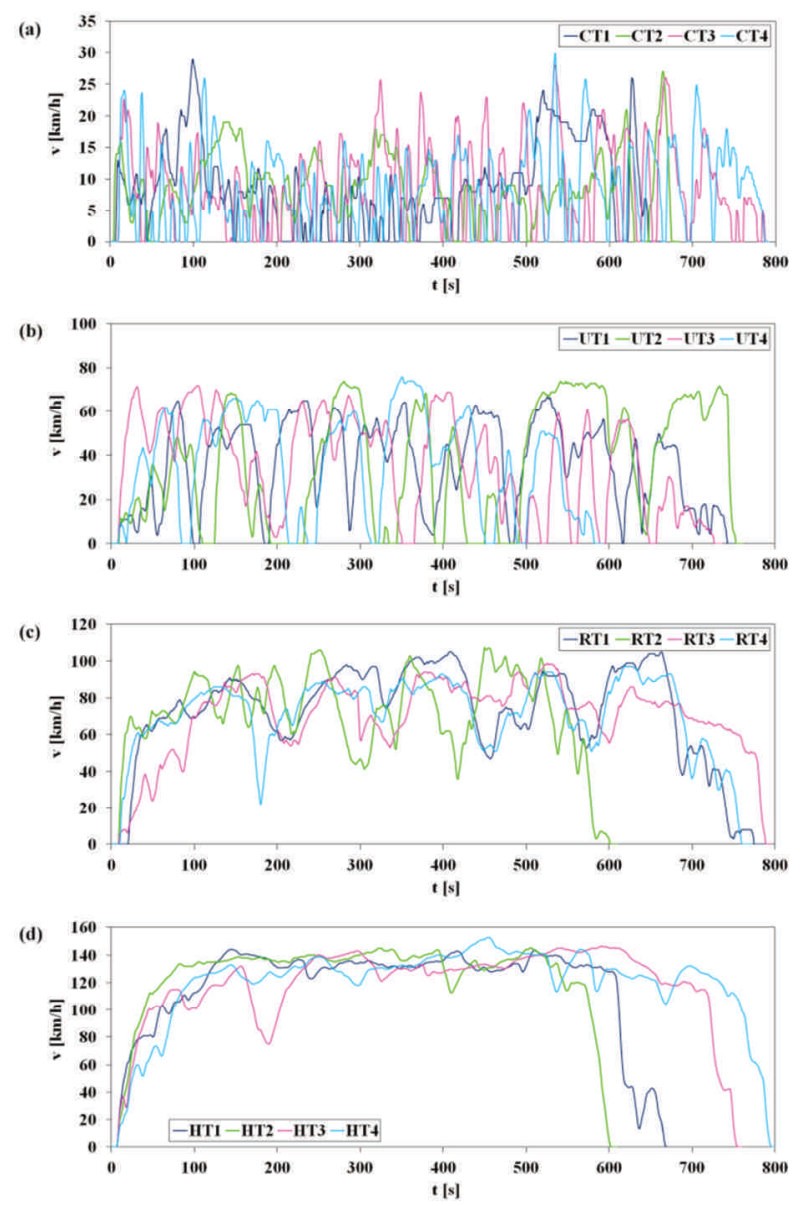

Fig. 2. Realizations of the vehicle velocity vs. time process for: a) urban traffic congestions (CT); b) urban traffic (UT); c) extra-urban traffic (RT); d) high-speed traffic (HT)

Further analysis of the vehicle velocity processes indicated certain diversity of the conditions of vehicle motion in individual driving cycles. It was based on the comparison between the coefficient of variation (CV) and the coefficient of interquartile range (CIQR, see (1)) determined for individual driving test cycles, for four test cycles of the same category, and for all the velocity samples collected in empirical investigation in real road traffic of the same category. The results of the analysis is shown in Figure 4.

$$
\mathrm{CIQR}=\frac{\mathrm{DQ}}{\mathrm{M}}
$$

As it was in the case of the results of examination of the maximum value, average value, median, standard deviation, and quartile deviation, a significant similarity was found to exist between the results of examination of the relative coefficients of variation and interquartile range. 
Table 1. Summary of basic characteristics of the designed vehicle driving test cycles

\begin{tabular}{|c|c|c|c|c|c|c|c|}
\hline $\begin{array}{l}\text { Vehicle opera- } \\
\text { tion model }\end{array}$ & $\begin{array}{c}\text { Test realization } \\
\text { symbol }\end{array}$ & $\begin{array}{c}\text { Distance } \\
\text { travelled } \\
\text { during the } \\
\text { test }[\mathrm{km}]\end{array}$ & $\begin{array}{l}\text { Test dura- } \\
\text { tion time } \\
{[\mathrm{s}]}\end{array}$ & $\begin{array}{c}\text { Share of time } \\
\text { when vehicle } \\
\text { velocity equals } \\
0 \\
{[\%]} \\
\end{array}$ & $\begin{array}{c}\text { Average } \\
\text { vehicle } \\
\text { velocity in } \\
\text { the test } \\
{[\mathrm{km} / \mathrm{h}]}\end{array}$ & $\begin{array}{c}\text { Minimum } \\
\text { vehicle veloci- } \\
\text { ty in the test } \\
{[\mathrm{km} / \mathrm{h}]}\end{array}$ & $\begin{array}{c}\text { Maximum } \\
\text { vehicle veloci- } \\
\text { ty in the test } \\
{[\mathrm{km} / \mathrm{h}]}\end{array}$ \\
\hline \multirow{4}{*}{$\begin{array}{l}\text { Urban traffic } \\
\text { congestions } \\
\text { (CT) }\end{array}$} & CT1 & 1.583 & 662 & 20 & 8.59 & 0 & 29.0 \\
\hline & CT2 & 1.620 & 684 & 13 & 8.51 & 0 & 27.0 \\
\hline & CT3 & 1.881 & 792 & 21 & 8.54 & 0 & 28.0 \\
\hline & CT4 & 1.862 & 792 & 19 & 8.45 & 0 & 29.9 \\
\hline \multirow{4}{*}{$\begin{array}{l}\text { Urban traffic } \\
\text { (UT) }\end{array}$} & UT1 & 7.528 & 751 & 5 & 36.04 & 0 & 67.0 \\
\hline & UT2 & 7.621 & 761 & 19 & 36.00 & 0 & 74.0 \\
\hline & UT3 & 7.366 & 736 & 9 & 35.98 & 0 & 72.0 \\
\hline & UT4 & 5.943 & 593 & 14 & 36.02 & 0 & 75.9 \\
\hline \multirow{4}{*}{$\begin{array}{l}\text { Extra-urban } \\
\text { traffic } \\
(\mathrm{RT})\end{array}$} & RT1 & 15.640 & 795 & 5 & 70.73 & 0 & 105.0 \\
\hline & RT2 & 11.981 & 610 & 3 & 70.59 & 0 & 107.3 \\
\hline & RT3 & 15.383 & 795 & 2 & 69.57 & 0 & 98.6 \\
\hline & RT4 & 15.172 & 772 & 3 & 70.66 & 0 & 97.0 \\
\hline \multirow{4}{*}{$\begin{array}{l}\text { High-speed } \\
\text { traffic } \\
(\mathrm{HT})\end{array}$} & HT1 & 21.745 & 672 & 2 & 116.32 & 0 & 144.0 \\
\hline & HT2 & 20.900 & 609 & 2 & 123.34 & 0 & 145.2 \\
\hline & HT3 & 24.865 & 760 & 2 & 117.63 & 0 & 146.4 \\
\hline & HT4 & 26.291 & 800 & 2 & 118.16 & 0 & 152.9 \\
\hline
\end{tabular}

(a)

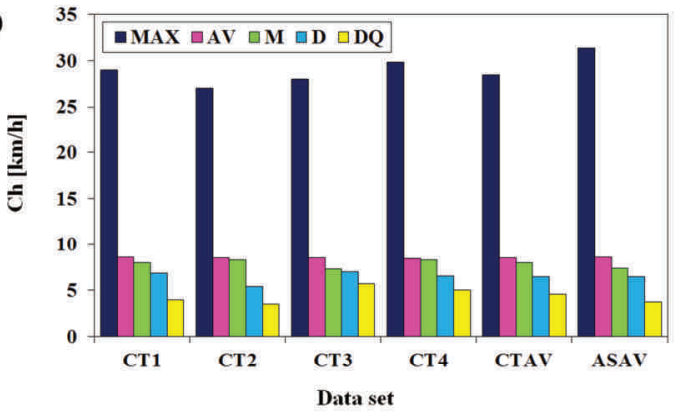

(c)

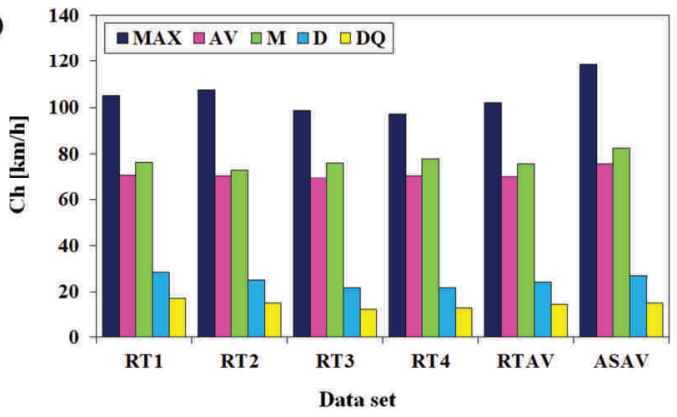

(b)

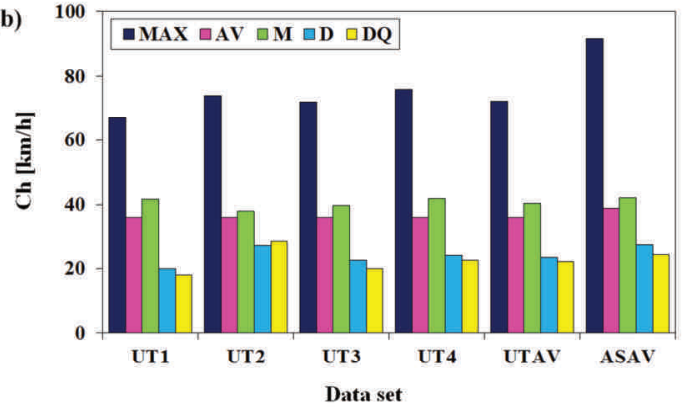

(d)

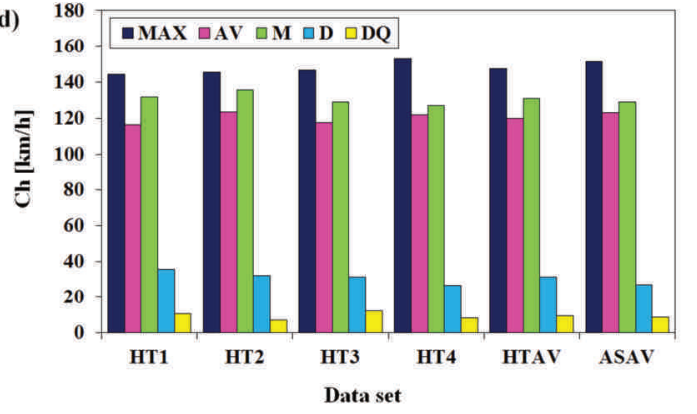

Fig. 3. Characteristics of the velocity process realizations in individual driving cycles, in sets of four cycles of the same category, and in all the velocity samples collected: a) urban traffic congestions (CT); b) urban traffic (UT); c) extra-urban traffic (RT); d) high-speed traffic (HT)

Figure 5 shows results of the analysis of vehicle driving test cycles at individual vehicle drive modes in the frequency domain. The analysis was carried out on standardized process values [5]. The standardized power spectral density was estimated with the use of the fast Fourier transform method. To improve the consistency of the power spectral density estimator, the Hamming window [5, 31] and frequency smoothing [5] techniques were applied in the data processing.

A comparison between individual vehicle driving test cycles in the frequency domain for all the vehicle drive conditions being modelled is presented in Figure 6. An analysis of the frequency characteristics of the vehicle velocity processes confirms that the vehicle operation conditions are most dynamic in the case of urban traffic conges- tions and the least dynamic in the case of high-speed traffic. According to this criterion, urban traffic without congestions and extra-urban traffic fall somewhere in between. It should be noted that high uniformity of the curves plotted for extra-urban traffic can be observed, in contrast to the curves plotted for high-speed traffic, which power spectral density is clearly divided into two ranges, especially for large frequency values.

The test analyses in the process value domain have been illustrated by investigations on the distribution of probability of the vehicle velocity. Figure 7 shows the discrete probability density $(\mathrm{g}[\mathrm{v}])$ of vehicle velocity $(\mathrm{v})$ in the individual driving test cycles for four categories of driving conditions. 

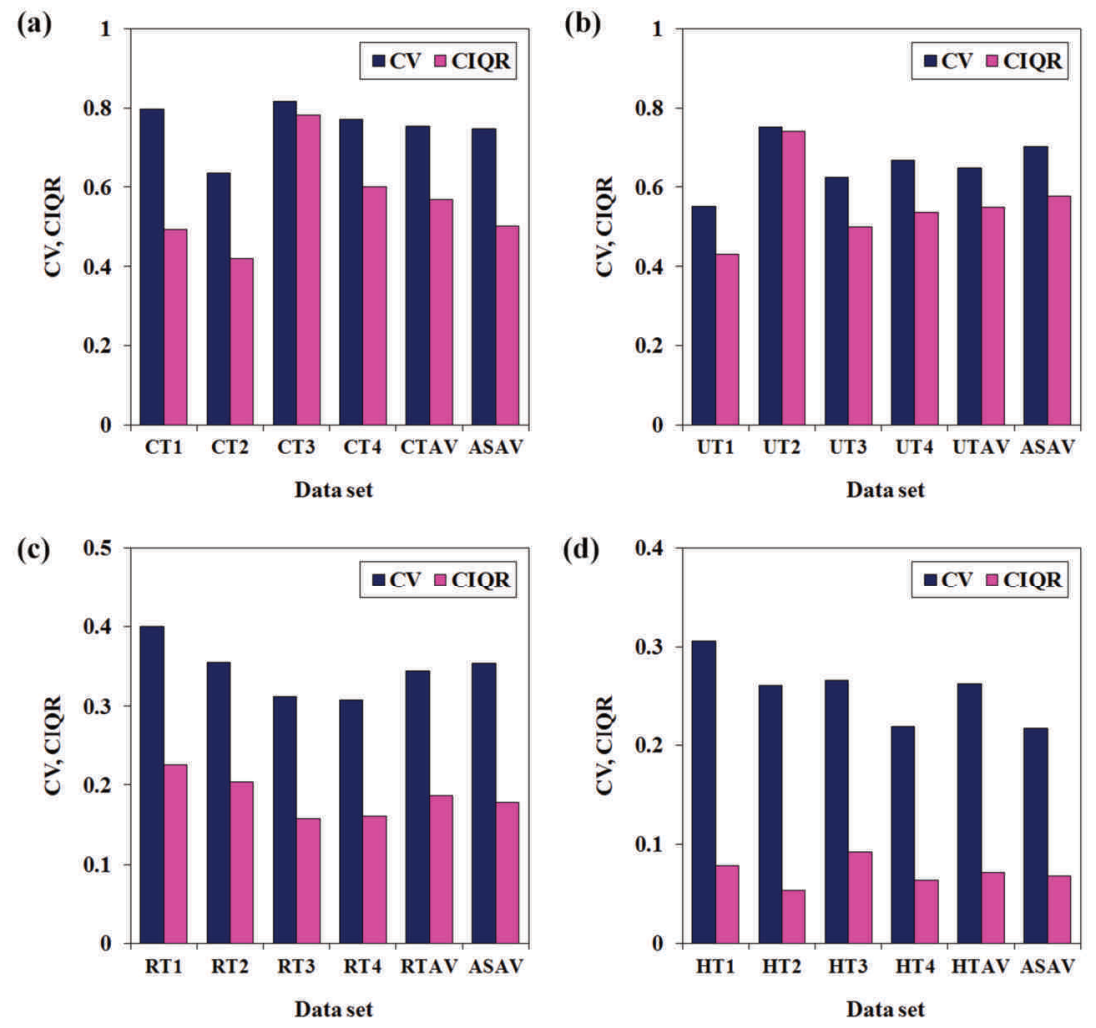

Fig. 4. Coefficient of variation (CV) and the coefficient of interquartile range (CIQR) for the velocity process realizations in individual driving test cycles, in sets of four test cycles of the same category, and in all the velocity samples collected: a) urban traffic congestions (CT); b) urban traffic (UT); c) extra-urban traffic (RT); d) high-speed traffic (HT)

(a)

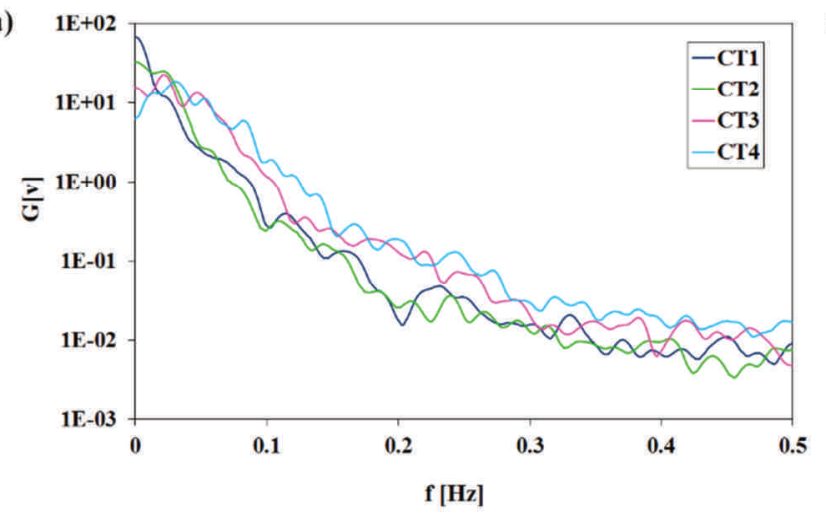

(c)

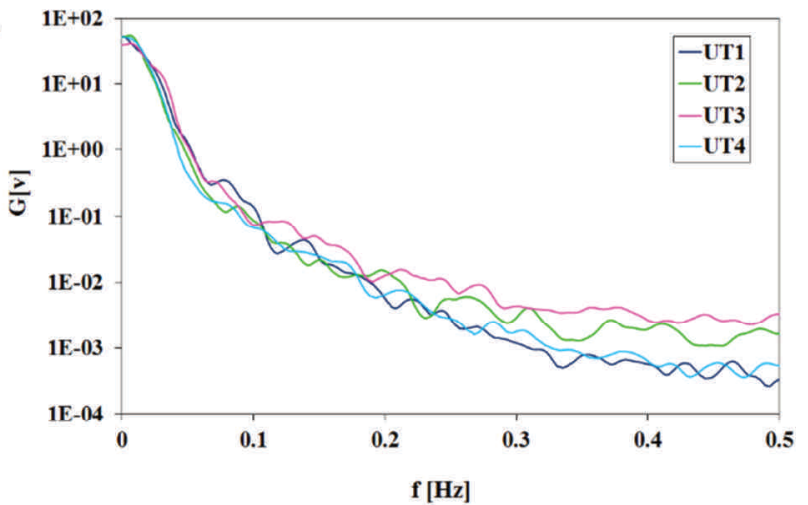

(b)

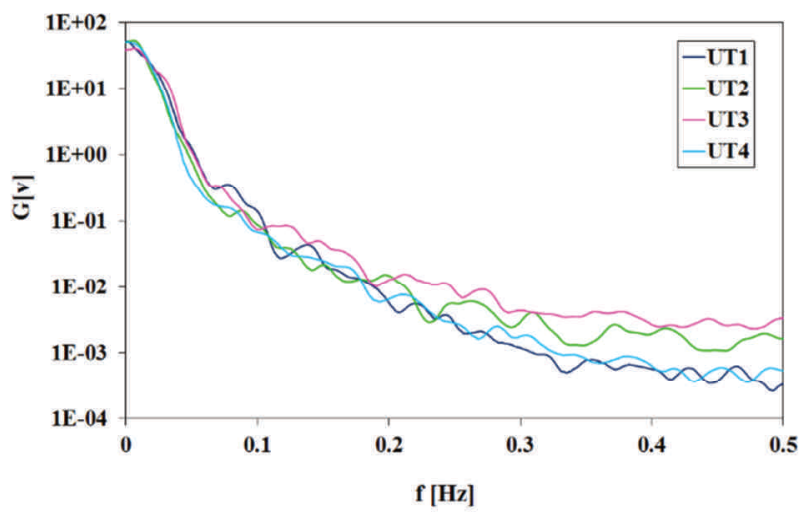

(d)

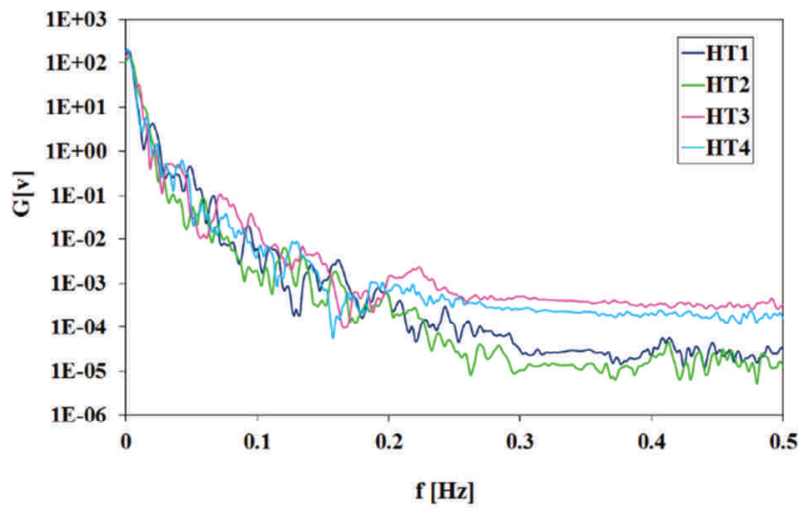

Fig. 5. The power spectral density of standardized velocity (G[v]) in the frequency domain (f) in the vehicle driving test cycles for: a) urban traffic congestions (CT); b) urban traffic (UT); c) extra-urban traffic (RT); d) high-speed traffic (HT) 


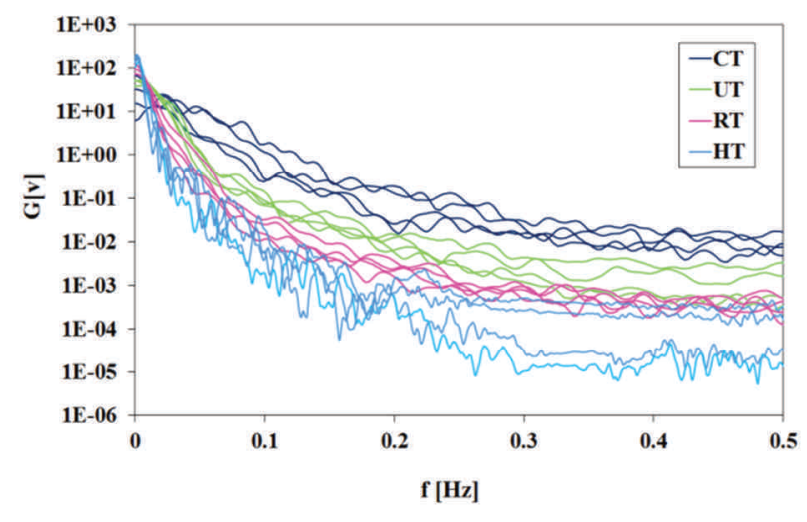

Fig. 6. Comparison between the curves representing the power spectral density of standardized velocity $(G[v])$ in the frequency domain (f) for all the vehicle operation conditions being modelled

The results of examination of the developed driving cycles in the process value domain confirm a significant similarity to exist between the properties of individual realizations of the tests. In spite of differences in the values of probability density in individual test realizations, the characteristics having been determined are similar to each other to a considerable degree.

(a)

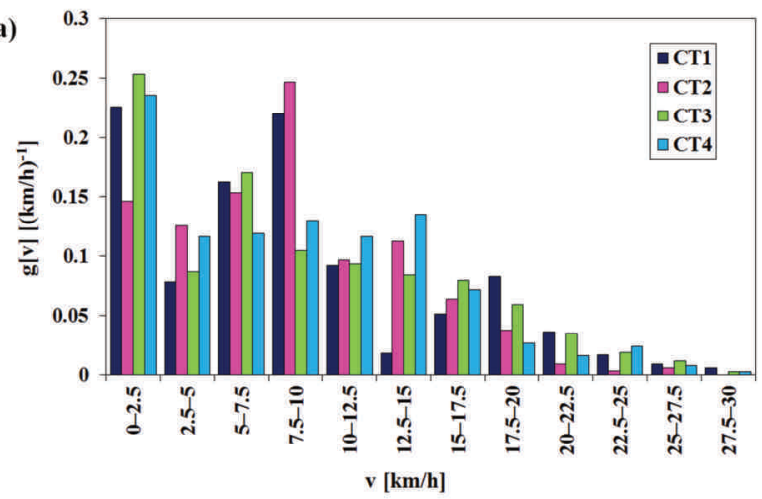

(c)

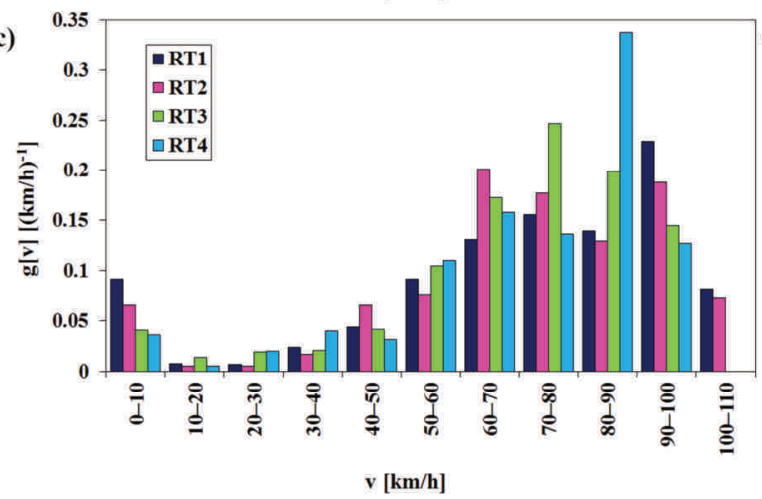

An analysis of properties of the special vehicle driving test cycles developed has provided grounds for a statement that the tests for a specific vehicle drive model correspond to vehicle drives in comparable vehicle operation conditions. Simultaneously, and in accordance with expectations, substantial differences exist between tests representing different vehicle drive modes. In respect of the average value and the maximum value of vehicle velocity, the vehicle drive models may be arranged as follows, in a growing order of the said values: street congestions, urban traffic, extra-urban traffic, and high-speed traffic. Apart from that, an analysis of the frequency characteristics of the vehicle velocity processes confirms that the vehicle drive properties are most dynamic in the case of drives in street congestions. The second most dynamic vehicle drive properties occur when the vehicle is driven in urban traffic. In the third and fourth positions in this ranking, the extra-urban traffic and high-speed traffic should be mentioned, respectively.

An important unique feature of the method of designing vehicle driving test cycles as proposed herein is the treatment of such tests as realizations of stochastic processes, thanks to which conclusions can be drawn about the sensitivity of functional properties of internal combustion engines not only to dynamic but also to random conditions of engine operation.
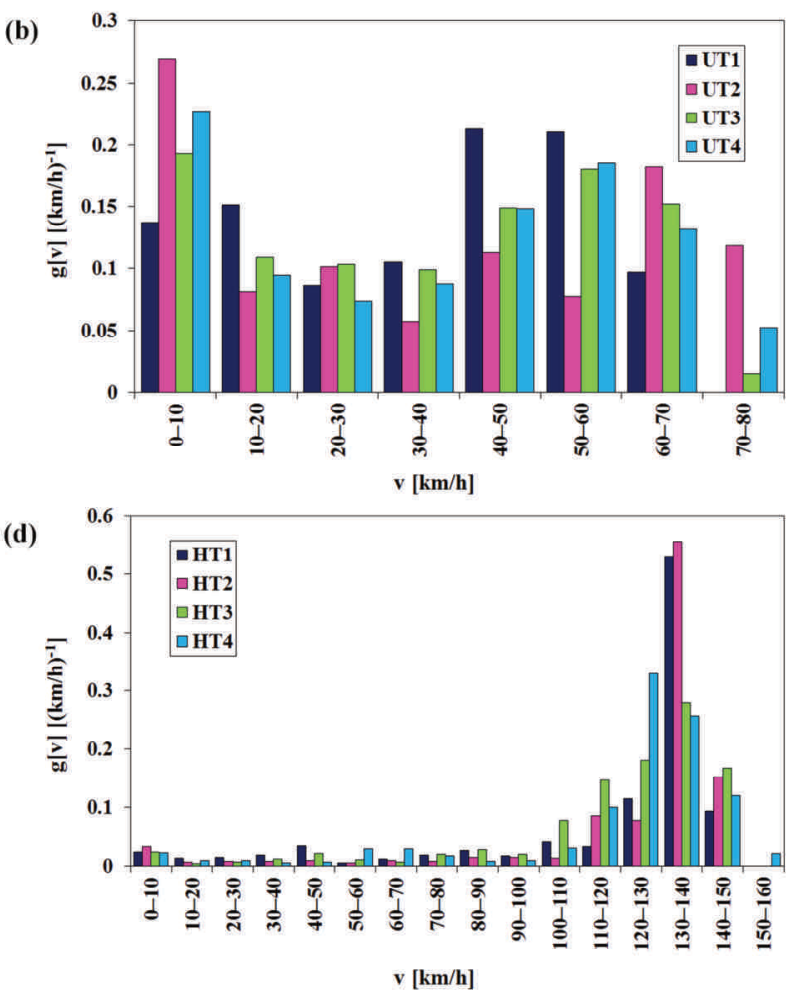

Fig. 7. Comparison between the discrete probability density (g[v]) of vehicle velocity (v) in the vehicle driving test cycles for: a) urban traffic congestions (CT); b) urban traffic (UT); c) extra-urban traffic (RT); d) high-speed traffic (HT)

\section{Conclusions}

The examination of motor vehicles by subjecting them to vehicle driving test cycles is the basic method of acquiring knowledge of the vehicle properties in conditions corresponding to the real vehicle operation. The examination of motor vehicles in vehicle driving test cycles is chiefly aimed at the evaluation of ecological vehicles' properties related to pollutant emission and their economic performance in terms of fuel consumption. Therefore, numerous works are undertaken on tests simulating various conditions of operation of motor vehicles, especially motor cars and light trucks, but also heavier trucks and buses [6]. Some of 
such tests have been given the status of criteria of evaluation of pollutant emission and fuel consumption in typeapproval procedures [13].

An overwhelming majority of the vehicle driving test cycles having been developed at numerous research and development centres have a causal (deterministic) nature (i.e. when applied as a test input, they determine the quantities measured as the test output). In this study, a concept has been presented where vehicle driving test cycles are treated as a set of realizations of stochastic processes, corresponding to motor car drives in the conditions of street congestions, urban traffic without congestions, extra-urban traffic, and high-speed (motorway and expressway) traffic. The tests have been prepared in the form of vehicle velocity process realizations, generated as faithful time-domain simulations with the use of results of empirical vehicle velocity measurements, recorded during typical vehicle operation. As the basic similarity criteria to be taken into account at the preparation of process realizations, the average value and standard deviation of vehicle velocity have been adopted.
The examination of the tests prepared, carried out in the time, frequency, and process value domains, has confirmed that individual process realizations are similar to each other and to all the process realizations recorded during the empirical tests.

The examination of motor vehicles with the use of vehicle driving test cycles treated as stochastic processes represented by process realizations provides a possibility of significant widening of the scope of the knowledge thus acquired, especially by enabling the evaluation of the uncertainty of results of measurements carried out in random vehicle drive conditions typical for the simulated vehicle operation mode. Example results of such investigations have been published $[11,12]$.

\section{Acknowledgements}

This paper is based on results of tests carried out within research grant No. N N509556440 entitled 'Sensitivity of pollutant emission and fuel consumption to the conditions of operation of a spark-ignition engine', sponsored by the National Science Centre of Poland.

\section{Nomenclature}

AV

BUWAL Bundesamt für Umwelt, Wald und Landschaft

Ch zero-dimensional characteristic

CIQR coefficient of inter-quartile range

CORINAIR Core Inventory of Air Emissions

CT

CV

$\mathrm{D}$

DQ

EUDC

FTP-75

HDDTC

HT urban traffic congestions coefficient of variation standard deviation quartile deviation extra urban driving cycle federal test procedure heavy duty diesel transient cycle high-speed traffic
IC

INFRAS Infrastruktur- Umwelt- und Wirtschaftsberatung

INRETS Institut National de Recherche sur les Transports et leur Sécurité

$M$

MAX

NEDC

OBD II

PIMOT

RT

UDC

UT

\section{median}

maximum value

New European Driving Cycle

on-board diagnostics system, II generation

Przemysłowy Instytut Motoryzacji (Automo-

tive Industry Institute)

extra-urban (rural) traffic

urban driving cycle

urban traffic (without congestions)

\section{Bibliography}

[1] ANDRÉ, M. The ARTEMIS European driving cycles for measuring car pollutant emissions. Science of the Total Environment. 2004, 334-335, 73-84.

[2] BANDO, M., HASEBE, K., NAKAYAMA, A. et al. Dynamical model of traffic congestion and numerical simulation. Physical Review E. 1995, 51(2), 1035-1042.

[3] BARLOW, T.J., LATHAM, S., MCCRAE, I.S., BOUTLER, P.G. A reference book of driving cycles for use in the measurement of road vehicle emission: version 3. TRL, United Kingdom 2009.

[4] BARTH, M., SCORA, G., YOUNGLOVE, T. Estimating emissions and fuel consumption for different levels of freeway congestion. Transportation Research Record: Journal of the Transportation Research Board. 1999, 1664, 47-57.

[5] BENDAT, J.S., PIERSOL, A.G. Random data: analysis \& measurement procedures. Wiley, New York 1966.

[6] BUWAL, INFRAS. Luftschadstoffemissionen des Strassenverkehrs 1950-2010: BUWAL-Bericht Nr. 255. BUWAL, Bern 1995.

[7] CHŁOPEK, Z. Modelling of exhaust emission processes in the conditions of operation of combustion engines in mobile applications. Publishing House of the Warsaw University of Technology. Warszawa 1999.

[8] CHŁOPEK, Z. The cognitive interpretation of the Monte Carlo method for the technical applications. Eksploatacja $i$ Niezawodnosc - Maintenance and Reliability. 2009, 43(3), 38-46.

[9] CHŁOPEK, Z. The research of the probabilistic characteristics of exhaust emissions from vehicle engines. Combustion Engines. 2011, 144(1), 49-56.

[10] CHŁOPEK, Z., BIEDRZYCKI, J., LASOCKI, J., WÓJCIK, $P$. Investigation of the motion of motor vehicles in Polish conditions. The Archives of Automotive Engineering - Archiwum Motoryzacji. 2013, 60(2), 3-20.

[11] CHŁOPEK, Z., BIEDRZYCKI, J., LASOCKI, J., WÓJCIK, $P$. Investigation of pollutant emissions from a motor vehicle engine in tests simulating real vehicle use in road traffic conditions. Combustion Engines. 2013, 154(3), 202-207.

[12] CHŁOPEK, Z., BIEDRZYCKI, J., LASOCKI, J., WÓJCIK, $P$. Pollutant emissions from combustion engine of motor vehicle tested in driving cycles simulating real-world driving 
conditions. Proceedings of the Institute of Vehicles. 2013 92(1), 65-74.

[13] DELPHI. 2016/2017 Worldwide Emission Standards: Passenger Cars and Light Duty. 2016.

[14] EEA. EMEP/CORINAIR Emission Inventory Guidebook 2007.

[15] GONG, Q., MIDLAM-MOHLER, S., MARANO, V., RIZZONI, G. An iterative markov chain approach for generating vehicle driving cycles. SAE International Journal of Engines. 2011, 4(1), 1035-1045.

[16] JACOBS, P.A. A random measure model for the emission of pollutants by vehicles on a highway. Stochastic Processes and their Applications. 1974, 2(2), 163-176.

[17] KELLER, M., WÜTHRICH, P. Handbook emission factors for road transport 3.1/3.2: Quick Reference. INFRAS AG, Bern 2014.

[18] LEE, T.-K., FILIPI, Z.S. Synthesis of real-world driving cycles using stochastic process and statistical methodology. International Journal of Vehicle Design. 2011, 57(1), 17-36.

[19] LIN, J., NIEMEIER, D.A. An exploratory analysis comparing a stochastic driving cycle to California's regulatory cycle. Atmospheric Environment. 2002, 36(38), 5759-5770.

[20] LYONS, T.J., KENWORTHY, J.R., AUSTIN, P.I., NEWMAN, P.W.G. The development of a driving cycle for fuel consumption and emissions evaluation. Transportation Research Part A: General. 1986, 20(6), 447-462.

[21] METROPOLIS, N., ULAM, S. The Monte Carlo method. Journal of the American Statistical Association. 1949, 247(44), 335-341.

[22] MILLER, A.J. Road traffic flow considered as a stochastic process. Mathematical Proceedings of the Cambridge Philosophical Society. 1962, 58(2), 312-325.

Prof. Zdzisław Chłopek, DSc., DEng. - Automotive Industry Institute in Warsaw.

e-mail: Zdzislaw.Chlopek@pimot.eu

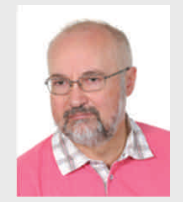

Jakub Lasocki, DEng. - Faculty of Automotive and Construction Machinery Engineering at Warsaw University of Technology.

e-mail:J.Lasocki@simr.pw.edu.pl

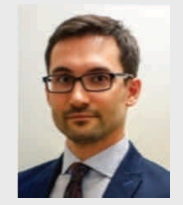

Izabela Samson-Bręk, MEng. - Liquid Fuels and Bio-economy Department at Automotive Industry Institute in Warsaw.

e-mail:I.Samson@pimot.eu
[23] NOLLET, V., SCHADKOWSKI, C., HUE, S. et al. Elaboration d'un cadastre d'émissions de polluants primaires dans la region Nord-Pas-de-Calais: Les transports automobiles. Pollution atmosphérique. 2000, 165, 109-119.

[24] PAPOULIS, A., PILLAI, S.U. Probability, random variables and stochastic processes. McGraw-Hill, New York 2002.

[25] SAVITZKY, A., GOLAY, M.J.E. Smoothing and differentiation of data by simplified least squares procedures. Analytical Chemistry. 1964, 36(8), 1627-1639.

[26] SCHWARZ, W. Consistent engine and vehicle modeling for real life fuel consumption and emission predictions. Paper presented at the AVL Sweden Seminar, Göteborg, November 7th 2012.

[27] SOUFFRAN, G., MIÈGEVILLE, L., GUÉRIN, P. Simulation of real-world vehicle missions using a stochastic Markov model for optimal design purposes. IEEE Transactions on Vehicular Technology. 2011, 61(8), 1-6.

[28] TONG, H.Y., HUNG, W.T., CHEUNG, C.S. Development of a driving cycle for Hong Kong. Atmospheric Environment. 1999, 33(15), 2323-2335.

[29] TREIBER, M., HENNECKE, A., HELBING, D. Congested traffic states in empirical observations and microscopic simulations. Physical Review E. 2000, 62, 1805-824.

[30] TRYON, R.C. Cluster analysis: correlation profile and orthometric (factor) analysis for the isolation of unities in mind and personality. Edwards Brothers, Ann Arbor 1939.

[31] TUKEY, J.W. An introduction to the calculations of numerical spectrum analysis. In: Spectral Analysis of Time Series, edited by B. Harris, 25-46. Wiley, New York 1967.

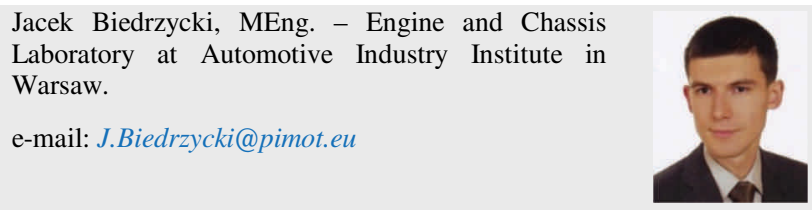

Piotr Wójcik, MEng. - Engine and Chassis Laboratory at Automotive Industry Institute in Warsaw.

e-mail:P.Wojcik@pimot.eu

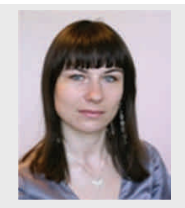

